\title{
Stability characteristics of wavy walled channel flows
}

\author{
S. Selvarajan \\ National A erospace Laboratories, Bangalore-560 017, India \\ E. G. Tulapurkara \\ Indian Institute of Technology, Madras-600 036, India \\ V. Vasanta Ram \\ Institut fur Thernio-und Fluiddynamik, Ruhr Universitat Bochumn D-44780, Germany
}

(Received 27 October 1997; accepted 3 November 1998)

The linear temporal stability characteristics of converging-diverging, symmetric wavy walled channel flows are numerically investigated in this paper. The basic flow in the problem is a superposition of plane channel flow and periodic flow components arising due to the small amplitude sinusoidal waviness of the channel walls. The disturbance equations are derived within the frame work of Floquet theory and solved using the spectral collocation method. Two-dimensional stability calculations indicate the presence of fast growing unstable modes that arise due to the waviness of the walls. Neutral stability calculations are performed in the disturbance wavenumber-Reynolds number $\left(a_{s}-R\right)$ plane, for the wavy channel with wavenumber $\mathrm{k}_{1}=0.2$ and the wall amplitude to semi-channel height ratio, E,.., up to 0.1 . It is also shown that the two-dimensional wavy channel flows can be modulated by a suitable frequency of wall excitation $\mathrm{co}_{\mathrm{g}}$, thereby stabilizing the flow. (C) 1999 A merican Institute of Physics. [S 1070-6631(99)02802-0]

\section{INTRODUCTION}

Viscous flow over moving wavy boundaries may be observed in several natural phenomena, viz., the generation of wind waves on water, the formation of sedimentary ripples in river channels and dunes in the desert, etc. The subject is also encountered in some industrial applications, e.g., a novel method of fluid transfer, which avoids internal moving parts, employs a duct with flexible walls so as to generate progressive transversal deflection waves. The problem is worthy of interest because unsteady fluid dynamics, such as this one, shows the time-dependent development of the viscous-inviscid interactions of the flow. One of the interesting physical mechanisms of the flow over wavy boundaries is the transition from laminar to turbulent flow, i.e., whether the critical Reynolds number (below which all the disturbances are damped) decreases for the rigid wavy boundaries and increases when subjected to certain forced excitation of the wavy wall, The identification of suitable excitation parameters to bring about the delay of transition continues to remain a central problem in flow management and control. However, it may be mentioned that it is not always appropriate to produce a delay in the transition to turbulence, especially in heat and mass transfer processes. The wavy-walled channel, with its crests and troughs of the waviness aligned crosswise to the flow direction, can be a model device employed for enhancing heat and mass transfer efficiency in industrial transport processes and in biomedical applications such as a blood membrane oxygenator and kidney dialysis.

In the study of fluid motions, the process of the laminarturbulent transition in wall bounded flows begins with instability in the form of linearly growing two-dimensional
Tollmien-Schlichting waves. The subsequent stages are characterized by the development of secondary instabilities and the appearance of three-dimensional effects.' However, the presence of surface waviness or roughness alters this scenario and leads to other bypass mechanisms that have not yet been investigated in detail. ${ }^{2}$ A critical evaluation of the linear stability theory of flows is presented in a recent review by Reed et al. ${ }^{3}$ Earlier, the shear flow over a wavy boundary and the effects of a flexible boundary on hydrodynamic stability characteristics have been studied by Benjamin, ${ }^{4,5}$ Landahl, ${ }^{\mathrm{b}}$ and Hains and Price.

The study of the stability of oscillatory wall 8 bounded flows is a relatively new topic. Grosch and Salwen observed that for small mean velocity perturbations the modulated flow was more stable than the steady flow and larger fluctuations produced an abnormally strong instability. Von Kerczek $^{9}$ performed a perturbation analysis of the linear equations about the critical Reynolds number. He found that modulation frequencies near that of the most unstable Tollmien-Schlichting (T-S) wave of the steady case stabilized the flow. At the critical Reynolds number of 5772.22, both very low and high frequencies tend to make the flow mildly unstable. He did not find any strongly unstable modes, in conflict with the results of Grosch and Salwen. ${ }^{8}$ Later, Singer et al. ${ }^{10}$ performed a direct numerical simulation of the transition in an oscillatory plane channel flow. Their results agreed well with those of von Kerczek ${ }^{9}$ and pointed out the lack of adequate resolution of the Stokes layer in the computation done by Grosch and Salwen. ${ }^{8}$ Recently Guzman and Amon studied the transitional flows in a convergingdiverging channel using Direct Numerical Simulation techniques.

In the present work, we examine the effects of small 


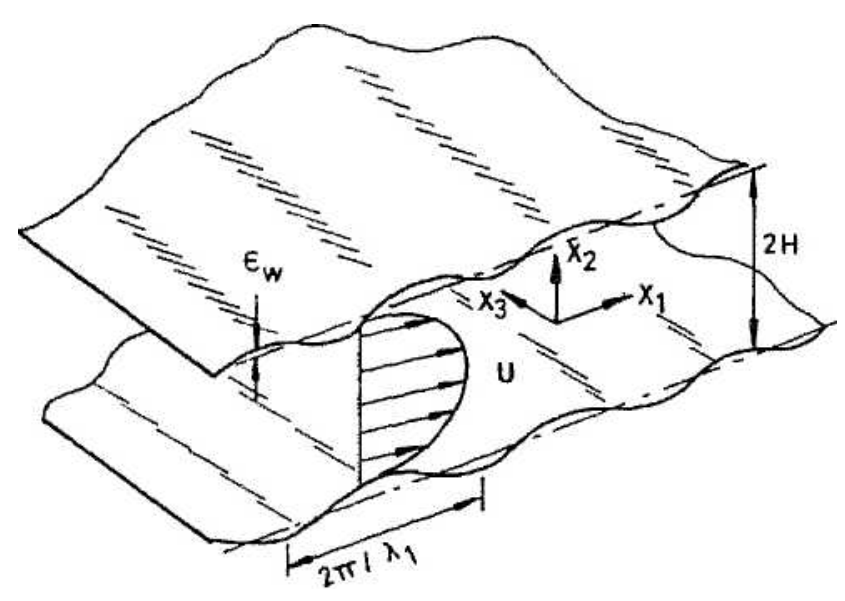

FIG. I. Schematic: of flow through a wavy walled channel.

amplitude sinusoidal converging-diverging waviness of the channel walls on the initial growth of the disturbances. The basic flow is comprised of time-independent plane channel flow and space- and timewise periodic flow components are induced due to the waviness of the walls which may be traveling. The theoretical frame work for the present study is the Floquet theory. Although the fornulation is general, we consider the two-dimensional problem and study two aspects, namely. (i) the variation in the critical Reynolds number with amplitude parameter and (ii) we show that it is possible to delay transition by a suitable excitation of the wall. The present work is different from a recent study by Floryan ${ }^{\text {" }}$ on the transition process in the presence of distributed roughness elements. In Floryan's study the sinusoidal distributed waviness is simulated by applying suction/blowing boundary conditions at the walls. In the present work, the flow configuration is such that the walls of the channel are considered wavy and no-slip boundary conditions are imposed on the surfaces. Furthermore, an excitation of the wall is permitted by prescribing a frequency, thus adding a parameter to Floryan's study. It is also appropriate to note that, with no excitation of the wall the physical problem of the flow past a wavy but rigid wall is equivalent in a first approximation to a suitable distribution of suction/ blowing at the plane wall surface.

\section{FORMULATION AND SOLUTION PROCEDURE}

The schematic of the flow configuration is presented in Fig. 1. The problem is formulated in two parts. First, the basic flow quantities are sought as perturbation from the parabolic profile of the fully developed channel flow and in the second part the Floquet theory is used to study the stability problem. Selvarajan and Vasanta $\operatorname{Ram}^{13}$ derived the governing equations for the basic and the disturbance flows in the most general form, and outlined a solution procedure. The salient features are presented here for the sake of clarity and completeness.

\section{A. Basic flow}

The nondimensional forms of the equations of motion for an incompressible fluid in the usual notation are

$$
\begin{aligned}
& c u / x_{1} O, j=1,-d, 3 \\
& \text { Oil i art; - op } 1 \quad \underline{\mathrm{Al}_{1}} \\
& \text { cit } \quad{ }_{1,2} x_{k} \quad \mathrm{ox}_{i} \quad R^{19}{ }^{19} \mathrm{YO}^{\frac{1}{4}} \quad j, k=1.2,3
\end{aligned}
$$

where the nondimensionalizing scales for length, velocity and pressure in that order are the mean semi-channel height. $H$ (see Fig.1) the mean center line velocity, $U$ and $p U^{2}$. The Reynolds number $\mathrm{R}$ is based on $H$ and $U$. We specify the wall motion $\mathrm{x}_{,,}$, through the following expression:

$\mathrm{x}, \mu .(\mathrm{t}, \mathrm{xt}, \mathrm{x} 3)= \pm 1+\mathrm{E}, . \operatorname{Re}[\mathrm{e}\{$ ifAt.r, $+\sim ;$ r 3 - et 1],

where $\operatorname{Re}($.$) denotes real part of (.) and i=y l-1$. Equation (2) represents a wave traveling in the plane of the wall around the position $\mathrm{x},{ }_{-} \pm 1$ with amplitude $\mathrm{s}, .$. , wavenumber vector $\left(X, I_{3}\right.$, and the frequency of excitation, $\left.u\right),,^{\prime}$ It may be pointed out that $\mathrm{g}$ and $\mathrm{w}$ are suffices and not indices. Further, it may be noted that the case of zero excitation corresponds to a rigid wavy boundary. Also, in the above form. the waves of the upper and lower walls are in anti-phase, so that at any instant of time the local channel width expands and contracts around the value $2 \mathrm{H}$.

For small amplitude of wavy wall excitation, the solution is sought as perturbation from the parabolic velocity profile, i.e.,

$$
\begin{aligned}
& u_{j}=S_{l j}(I-x ;)+e, . . c t j+O(E, . .), \\
& \mathrm{p}=-(2 \times 1 / \mathrm{R})+\mathrm{s}, ., \mathrm{p}+\mathrm{O}(\mathrm{e}),
\end{aligned}
$$

where the suffix iv refers to the wall. Transferring the boundary conditions in Eqs. (2) to the mean position of the wall, using standard methods, ${ }^{14}$ we get the boundary conditions for the perturbation ${ }_{a c} t$ as follows:

$$
\begin{aligned}
& \left.\mathrm{u} 1( \pm 1)=-2 \operatorname{Re}\left[\mathrm{e}^{\prime}\left(1 \mathrm{t} .{ }^{\prime} \mathrm{I}+\mathrm{a} 3 . \mathrm{r}\right\} \quad \mathrm{wt}\right)\right] \\
& \left.I t,(-!-1)=\operatorname{Re}\left[ \pm \mathrm{iceRe} \mathrm{e}^{\prime} 1 \sim \sim-\mathrm{Y} \mathrm{t}+\sim \sim \mathrm{x} 3 \mathrm{w} 5 \mathrm{t}\right)\right] \\
& \mathrm{u} 3(\{1)=0 .
\end{aligned}
$$

The boundary conditions (4a)-(4c) are directly obtained by applying no-slip boundary conditions at the walls. It may be noted that for the case of flow through rigid wavy channels, the frequency of excitation $\mathrm{w}_{\mathrm{g}}=0$, reducing the normal velocity component at the wall to be zero, i.e.,

$$
u 2\left({ }^{\prime} \pm 1\right)=0 \text {. }
$$

In contrast, Floryan ${ }^{\text {t2 }}$ applies a nonzero suction/blowing boundary condition at the plane wall surface which is dependent on the wavenumber of the distributed roughness to be simulated. However, in the present study, prescribing a nonzero normal velocity component at the wall implies that the wall is moving with a phase velocity. The solution for the above boundary conditions then assume the form

$$
\begin{aligned}
& t /=\frac{1}{2} i l_{i}(x,) \exp \left\{i\left(k_{l} x_{l}+X_{l} x_{3}-w_{g} t\right)\right\} \\
& +\mathrm{i}^{\prime}(\mathrm{x},) \exp \left\{-\mathrm{i}\left({ }^{\prime} \backslash 1 \mathrm{x} 1+\mathrm{X} 1 \mathrm{x} 3-\mathrm{w}_{\mathrm{g}} \mathrm{t}\right)\right\} \\
& 1 p\left(x_{2}\right) \exp \left\{i\left(X_{l} x_{l}+X_{I} x_{3}-w_{g} t\right)\right\} \\
& \mathrm{P} \quad 2+\mathrm{p}^{*}(\mathrm{x},) \exp \left\{-\mathrm{i}\left(\mathrm{X}_{1} \mathrm{x}_{1}+\mathrm{X}_{1-3}-\mathrm{w}_{\mathrm{g}} \mathrm{t}\right)\right\},
\end{aligned}
$$



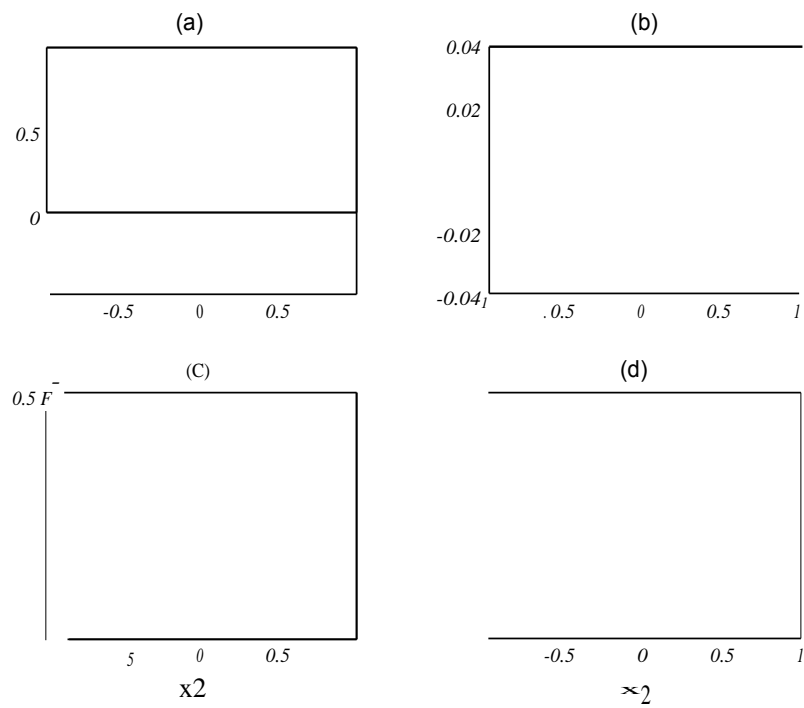

FIG. 2. The variation of amplitude functions of the periodic flow components (a) $1 \mathrm{i}_{2} . .$, (b) 1120 (c) it,, and (d) $\mathrm{a}_{1}$; for $\mathrm{R}=5772$. (i) Two-dimensional wavy channel flow (-); $\mathrm{k},=0.2, \mathrm{w}_{A}=0.0$; and (ii) plane channel flow $\mathrm{a}_{\mathrm{TS}}=1.02056, \mathrm{~W}_{\mathrm{TS}}=0.26,\left(-^{\prime}-.-.-\right)$.

where $u_{j}, p$ are amplitude functions to be regarded complex and the superscript $*$ denotes the complex conjugate. Substituting Eqs. (5) in Eq. (1) and linearizing yields the following equations:

$$
\begin{aligned}
& \mathrm{ik} l u t+{ }_{2}^{d u 2 d}+\mathrm{iX}_{3} \mathrm{u}_{3}=0, \\
& w_{9}+\left(1^{-} x \hat{2}\right) X \mid \jmath u 1-2 \times 2 \mathrm{u} 2 \\
& =-i x_{1} \mathrm{p}+(1 / \mathrm{R})(-\mathrm{X}-13)+\underbrace{c l^{2}}_{2} \mathrm{u}
\end{aligned}
$$

$\left.w_{\mathrm{b}}+\left(1^{-} \times 2\right) \sim \mathrm{t}\right] \mathrm{u} 2$

$$
\left.--i \times 1 \frac{d p}{d \times 2}+(1 J R) \quad{ }_{l}-A_{3}^{2}\right)+\frac{d^{2}}{d x 2} u_{2}
$$

$$
\begin{aligned}
& i\left[-\quad+\left(1^{-} \times 2\right) X 1\right] \text { at3 } \\
& =-i \times 3 p+(1 / R)(-)<1 \quad 3)+\frac{d^{2}-}{\overrightarrow{\partial x}_{2} U 3 .}
\end{aligned}
$$

Equations (6a)-(6d) are solved along with the following boundary conditions due to wall excitation:

$$
i_{1}(+1)=-2 ; \quad \mathrm{u}_{2}(! 1)= \pm \mathrm{iw}_{\mathrm{g}} ; \quad \mathrm{ic}_{3}( \pm 1)=0 .
$$

The solution of the basic flow is obtained numerically by solving the boundary value problem using two independent numerical procedures: (i) the finite difference method of Scott and Watts, and (ii) the spectral collocation method by Canuto et at. Both the numerical methods produced the same results with an accuracy of four decimal places. The details are presented in Selvarajan et ${ }^{\text {at. }}{ }^{17}$ In the present work, we restrict our attention, as already stated, to the case of two-dimensional wavy channel flows, i.e., X3=0 throughout the study. The flow parameters of interest mainly corre-
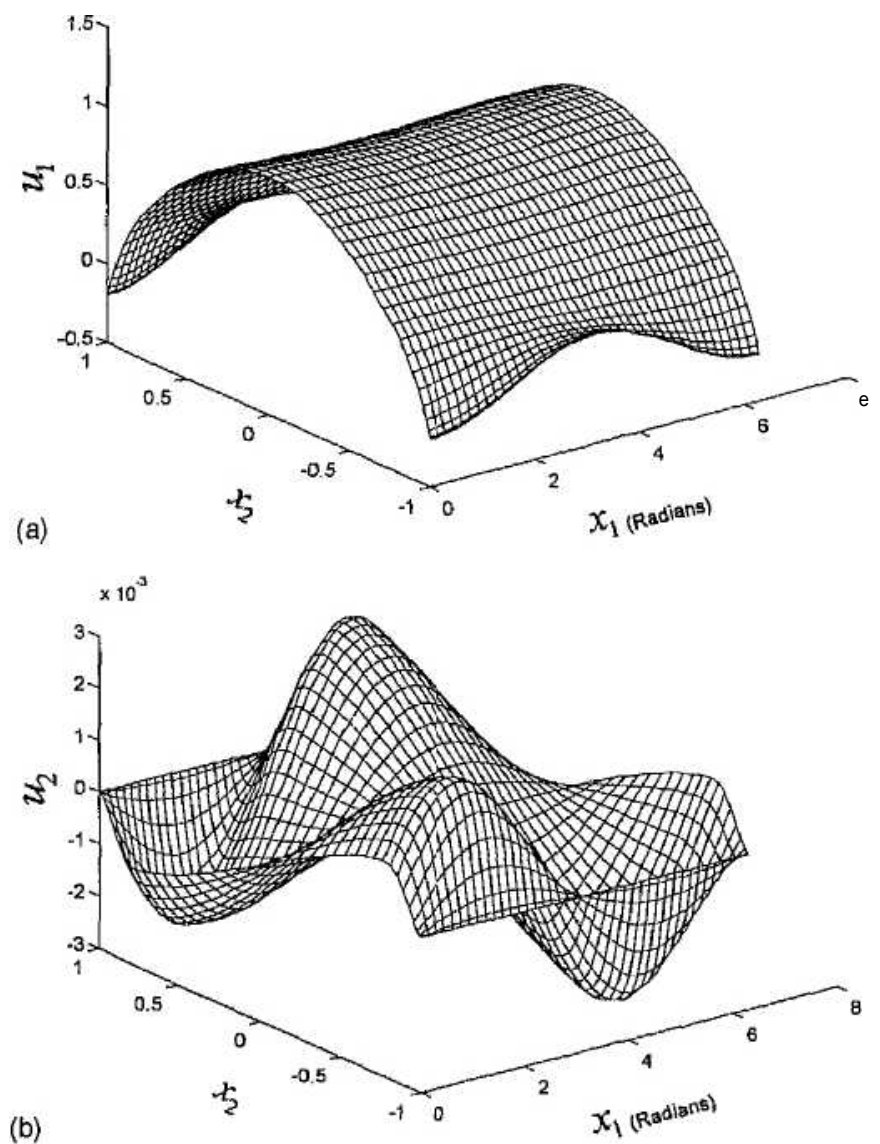

FIG, 3. (a) A mesh plot of the basic (base) flow velocity it, along the streamwise direction $\mathrm{x}_{\mid}$and normal direction, $x_{2}$, i.e., $\left\{u_{\uparrow}=(1-x\right.$, $)$ $+8,,, t$,$\} fork =0.2, \mathrm{X}_{3}=0.0, \mathrm{w}_{\mathrm{s}}=0.0$, and $\mathrm{s}, . .=0.1$; and $(\mathrm{b})\left\{\mathrm{u} 2=\mathrm{e},, \mathrm{u}^{\prime},\right\}$ for the above parameters.

spond to the critical parameters of the two-dimensional plane channel flows. We also consider the wavenumber of the wavy surface to be shallow with respect to the wavenumber of the disturbances. For the basic flow with 1. $=0.2, X_{3}$ $=\mathrm{O}, \cos _{\mathrm{s}}=0$, and $R=5772$, the typical variation of $\mathrm{u}_{\mathrm{I}}$ and $\mathrm{t}$, with $\mathrm{x}_{2}$ comprising of real and imaginary parts (it $\mathrm{li}_{\mathrm{i}}$..te ${ }_{\mathrm{ti}}$ ) and $(u),-. u 21)$ are shown in Fig. 2. Here the additional suffices $r$ and $i$ indicate real and imaginary parts, respectively. Also shown are the variations of the eigenfunctions that correspond to the critical parameters of the plane channel flow $\left(R=5772, \mathrm{X}_{1}=1.02056\right.$, and $\left.w .=0.2640\right)$. The variations of ${ }_{t c t}([\mathrm{X} 1=8,1(1-\mathrm{X} ;) \mathrm{I}-\mathrm{s},,, \mathrm{cc}]$,$) and u,\left(c c_{2}=e,, i c_{2}\right)$ for $\mathrm{e}$, , $=0.1$ are shown in Fig. 3(a) and Fig. 3(b), respectively. The nonzero velocity distributions along the mean surfaces of the walls are indicative of the no-slip boundary condition being satisfied on the wavy surface.

\section{B. The disturbance flow}

To study the stability of the wave-excited channel flow a further disturbance is introduced. This disturbance flow is of the following form:

$$
\begin{aligned}
& I^{\prime} 1=81(1-x 2)+a,,, i 6_{i}+e 11,1 \\
& p=-(2 x t / R)+E Y 4, p+s, . p s
\end{aligned}
$$


Here the suffix s, like $w$ and $g$, is not an index, but refers to a further disturbance. Substituting Eqs. (8) in Eqs. (1) and assuming that $\mathbf{e},<\mathbf{e},,,<<1$, the linearized equations of motion for the further disturbances are

$$
\begin{aligned}
& \text { atl }, j \\
& d X_{j} \\
& a_{s,+(I-X ;)_{a, ., 1}}-2 \times 211 s 2+a p s
\end{aligned}
$$

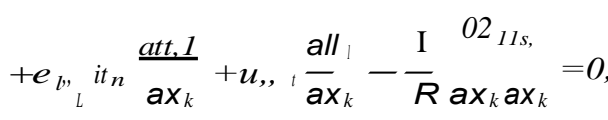

$$
\begin{aligned}
& \begin{array}{c}
\text { all, }+(\mathrm{I} \quad \text { ap, } 2+a P s \\
\text { at }
\end{array}
\end{aligned}
$$

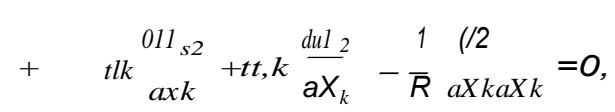

$$
\begin{aligned}
& a n_{5} 3 \quad, a / C_{s} 3 \quad a p, . \\
& \text { C? }+(I-z \cdot) a x,+a x_{e}
\end{aligned}
$$

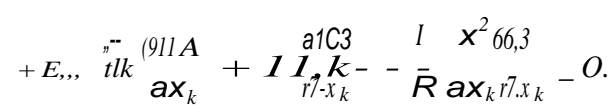

The periodic flow quantities $\mathrm{u}_{k}$ and $\mathrm{p}$ in Eqs. (9a)-(9d) are obtained from the computation of the basic flow as outlined in Sec. II A. Although the solution is first order accurate, it is adequate for the present investigation in which e,, is small. ${ }^{17}$ The practical limit on s,,, may be dictated by flow separation characteristics behind the wave-crest, which depend on Reynolds number R, wavenumber $X_{\text {I, }}$ and wall amplitude s,, itself.

The outstanding feature of the set of disturbance equations (9) that demarcates it from the classical stability problem is the presence of periodic terms in $t, x$, and $\mathrm{x}_{3}$ through $U k$. It implies that, although the parameter $\mathrm{a},$, . is small, the structure of the solution may be drastically changed by the periodic terms, Using the Floquet theory's Eqs. (9) can be transformed into ordinary differential equations, i.e., we express $u, k$ and $\mathrm{p}$, as follows:

$$
\begin{aligned}
& \left.u S k=11=Z_{\times} \operatorname{As}^{\prime} 1(\mathrm{x},) \exp \left[\mathrm{i} \sim \mathrm{ps}^{\prime \prime}\right)\right], \quad k=1,2,3 \\
& P s=\quad \operatorname{As}^{l}\left(x_{2}\right) \exp \left[\mathrm{icp},{ }^{\circ}\right],
\end{aligned}
$$

where

$$
l p,=(a,+i l k,) \times 1+(R, .+n X 3) \times 3-(w, .+n w d t,
$$

and $\mathrm{A}_{\mathrm{s} 1}, \mathbf{A}_{\mathrm{s} 2}, \mathrm{~A}_{3}{ }_{3}$ and $\mathrm{A}_{\mathrm{s} 4}$ are the amplitude functions. The expressions in Eqs. (10) represent superposition of waves of wavenumber (,3,5+taY 3$)$, and frequency (w, $+n w_{t}$ ). In the temporal stability problem, a, and ,6, are the disturbance wavenumbers and are prescribed as real. The solution of the problem then yields the complex frequency, co, for which Eqs. (9) admit nontrivial solutions. The imaginary part of $w$, then indicates the growth or decay of the further disturbance characterized by $(a, / 3$,$) . We write the$ dispersion relation of the problem symbolically in the following form:

$$
F(w s, c e, 5,, 3 .,, \mathbf{R}, \mathbf{E},,, \mathbf{X i}, A 3,(o s)=O,
$$

which shows the additional parameters, viz., e,,,, X1' 1t and $w_{x}$ that enter the problem due to the wave excitation of the wall.

The equations governing the amplitude functions $\mathrm{A}\left({ }^{\prime} \mathrm{i}(\mathrm{x} 2)\right.$ to $A\left(4^{\prime}\left(x_{2}\right)\right.$ are as follows:

$$
\begin{aligned}
& i(a,+n X,) A S^{\prime} \sim 1+-\frac{d \underline{A} s 2^{\prime}}{d x_{2}}+i(,(3, .+17 X 3) A s 3)=0, \\
& \mathrm{i}\{-(\mathrm{w}, .+\mathbf{n} . \mathrm{w} \sim) \mathbf{a}-(\mathbf{a},, .+\mathbf{n}>\mathbf{L},)(\mathrm{I}-x 2)\} A\left(., 1^{\prime \prime}\right)-\mathbf{2}_{\mathrm{x} 2 \mathrm{~A} ., \mathrm{z}}
\end{aligned}
$$

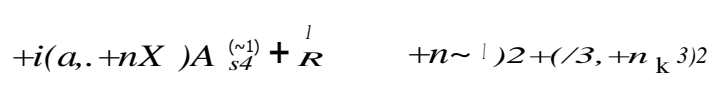

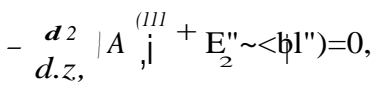

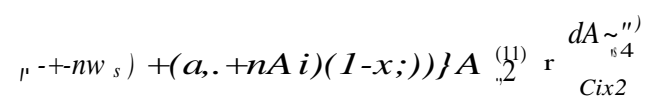

$$
\begin{aligned}
& +a(a,: l l \sim l) \\
& d X 2 \\
& +{ }_{2}^{I t,}\left(b_{2}^{\left({ }^{\prime \prime} l\right.}=O\right. \text {, }
\end{aligned}
$$

$i\left\{-(w, .+r t w \sim)-I-(c>,+r r A i)\left(1-. . t 2^{\top}\right\}\right\} A 2^{\prime}-I$

$$
\begin{aligned}
& +\frac{1}{R}\left\{\left(\alpha_{s}+n \lambda\right)^{2}+\left(\beta_{s}+n \lambda_{3}\right)^{2}-\frac{d^{2}}{d x_{2}^{2}}\right. \\
& +\dot{2}^{\circ}(1) \stackrel{0,1}{=}=0 .
\end{aligned}
$$

The quantities (hj" ', with $\mathrm{j}=1,2,3$, in Eqs. (12) are an abbreviation for the following expression:

$$
<l>\sim ")-\sim \text { ilal }\{a,+(n-I \quad i d l,,\{13,+(n-1) X 3\}
$$

$$
\begin{aligned}
& \left.\mid \boldsymbol{i l}, \underset{C{ }^{\prime} l . C 2}{c i} \boldsymbol{A},(), 1--1\right)^{-1} \mid \quad \text { is }\left\{c x,-+-\left(n-1+l 7 X_{\mid}\right\}\right. \\
& +i n_{31}\left(g_{,, .}-I-\left(/ /^{\prime}-I-1\right)_{X 3\}^{-I-a}}\right. \text { A 'r.l,i.It }
\end{aligned}
$$

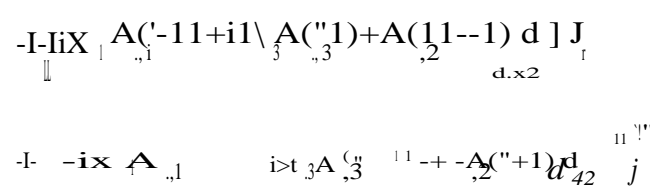

To bring out the differences between studies of the stability of the flow with a wave excited wall and the classical problem more clearly, it is meaningful to rewrite the ordinary differential equations for the complex amplitude functions in a form in which the contribution of the Orr-Sommerfeld 
TABLE 1. The least stable / most unstable modes for the wavy channel flow with $\mathrm{e}_{\text {,., }}$ as parameter $\mathrm{R}=5772, \mathrm{~K}_{\mathrm{I}}=0.2, \mathrm{a},=1.02056$,

\begin{tabular}{ccccccc}
\hline \multicolumn{4}{c}{ Mode 1(TS) } & \multicolumn{2}{c}{ Mode 2 } & \multicolumn{2}{c}{ Mode 3 } \\
$\mathrm{E}_{\mathrm{k} . .}$ & $\mathrm{t}^{\prime} \mathrm{i}$, & ilsli & Ws2r & Ws2i & ${ }^{(11} \mathrm{r} 3 \mathrm{r}$ & ws3i $^{2}$ \\
\hline 0.00 & 0.26944 & 0.000000 & & & & \\
0.01 & 0.26904 & 0.000001 & 0.19468 & -0.00621 & & \\
0.02 & 0.26789 & 0.000010 & 0.19429 & -0.00575 & & \\
0.03 & 0.26604 & 0.000054 & 0.19362 & -0.00497 & & \\
0.04 & 0.26362 & 0.000156 & 0.19267 & -0.00386 & & \\
0.05 & 0.26078 & 0.000330 & 0.19142 & -0.00240 & & \\
0.06 & 0.25765 & 0.000574 & 0.18985 & -0.00057 & & \\
0.07 & 0.25440 & 0.000872 & 0.18793 & 0.00164 & & \\
0.08 & 0.25155 & 0.001202 & 0.18563 & 0.00422 & & \\
0.09 & 0.24803 & 0.001550 & 0.18293 & 0.00718 & & \\
$(1.10$ & 0.24512 & 0.001914 & 0.17979 & 0.01047 & & \\
0.20 & 0.23021 & 0.009806 & 0.17623 & 0.02055 & 0.13018 & 0.05148 \\
0.30 & 0.22293 & 0.020615 & 0.11229 & 0.06565 & 0.06897 & 0.09624 \\
& & & & & & \\
\hline
\end{tabular}

part, and the additional terms can be more easily recognized. We therefore subject Eqs. (12) to the following steps which eliminate pressure.

Step 1: Multiply Eq. (12b) by $\left(\mathrm{a}, .+\mathrm{nX} \mathrm{X}_{\mathrm{i}}\right)$ and Eq. (12d) by $\left(8,+n X_{3}\right)$ and add the expressions.

Step 2: Differentiate the outcome of step 1 with respect to $\mathrm{x}_{2}$.

Step 3: Multiply Eq. (12c) by $[-\mathbf{i}\{($ as $+o X l) 2+(/ 3$, $\left.\left.\left.+11 \mathrm{X}_{3}\right)^{2}\right\}\right]$

Step 4: Add step 3 to step 2.
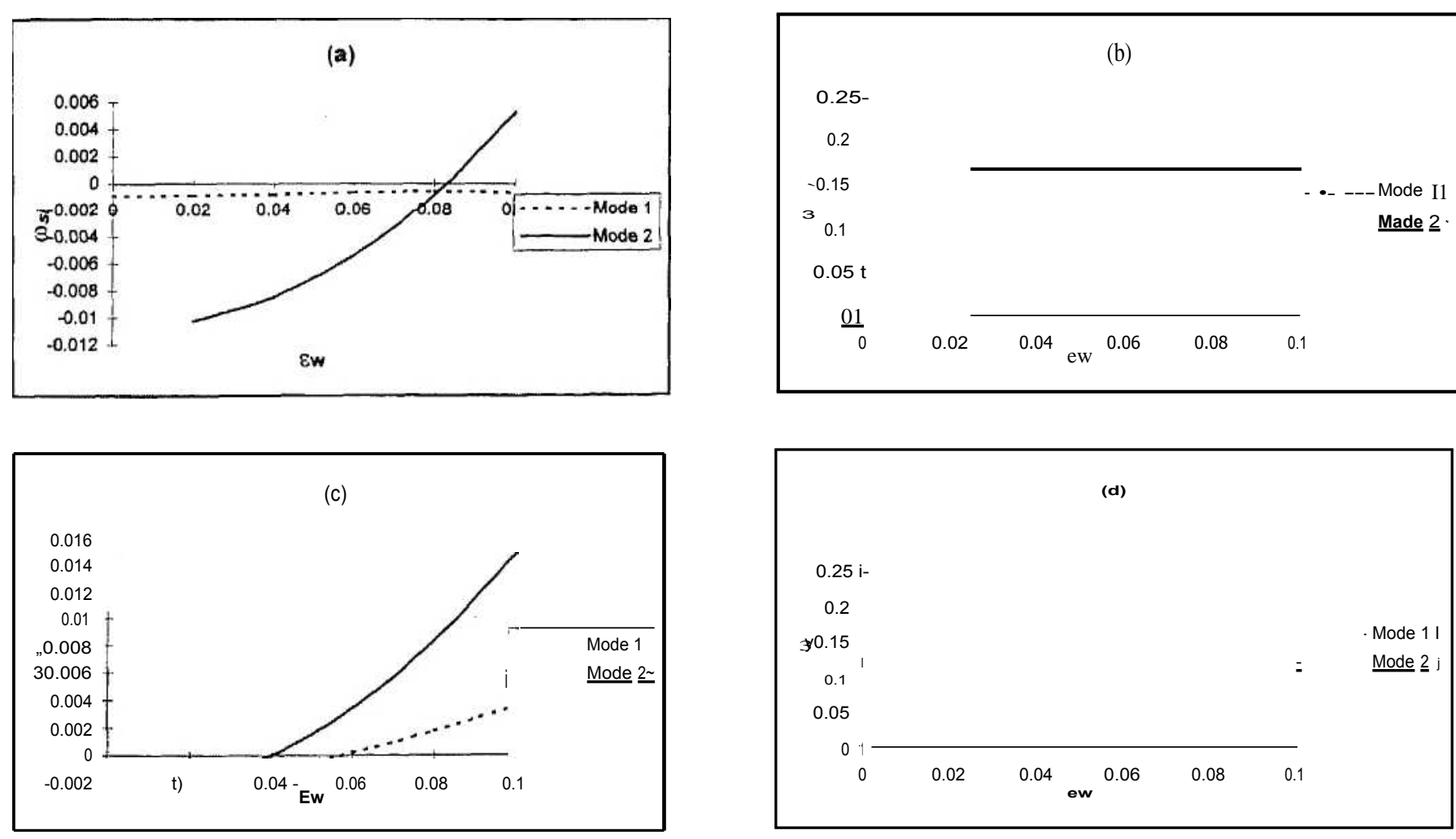

FIG. 4. Variation of the growth rate ((o) and circular frequency, $(\mathrm{r} \sim,$.$) with the wall amplitude \mathrm{s},$, , for the basic flow $\mathrm{R}=5772, \mathrm{X} \quad \mathrm{l}=0.2$ and $(\mathrm{a}) \quad a$, $=0.95$, imaginary part, (b) cr,. $=0.95$, real part, (c) a, $=1.10$, imaginary part, and (d) $\mathrm{a},=1.10$, real part.

Step 5: Multiply Eq. (12b) by $\left(8,+n X_{3}\right)$ and Eq. (12d) by $\left(a,,+n X_{1}\right)$ and subtract the expressions.

The resulting equation after steps I to 4 is

$$
d
$$

$d z^{2}$ $\underline{d A l,}{ }^{2}$

$\left.-\left(a_{s}+n X_{1}\right) X_{2}\left(2 \mathrm{x}_{2} A s\right)\right)+\mathrm{k} ;\{-(\mathrm{w},+\mathrm{nwg})$

$+(a, .+n \times 1)(1-x 2)\} .032$

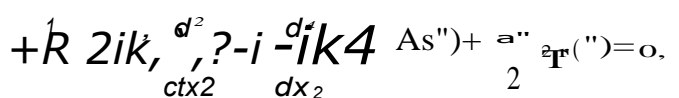

where the abbreviation $k$ stands for

$$
\left.k_{1}^{\prime \prime},=(a,+n X 1) 2+\quad+n X 3\right) 2 .
$$

The quantity ${ }_{\mathrm{NIr}}^{(n)}$ in Eq. (14) is a sum of thirteen terms, i.e.,

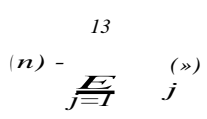

The ${ }_{N I I j^{\prime \prime}}$ are listed in Appendix A.

Equation (17) given below is the outcome of step 5, i.e.,

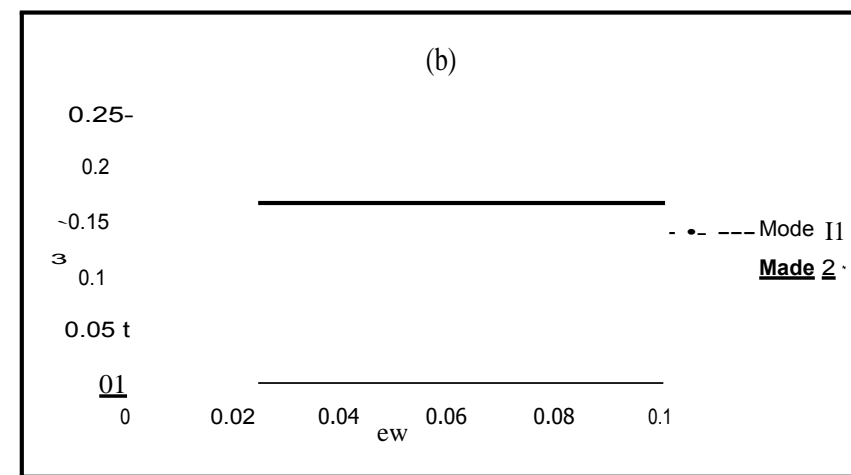


$584 \quad$ Phys. Fluids, Vol. 11, No. 3, March 1999

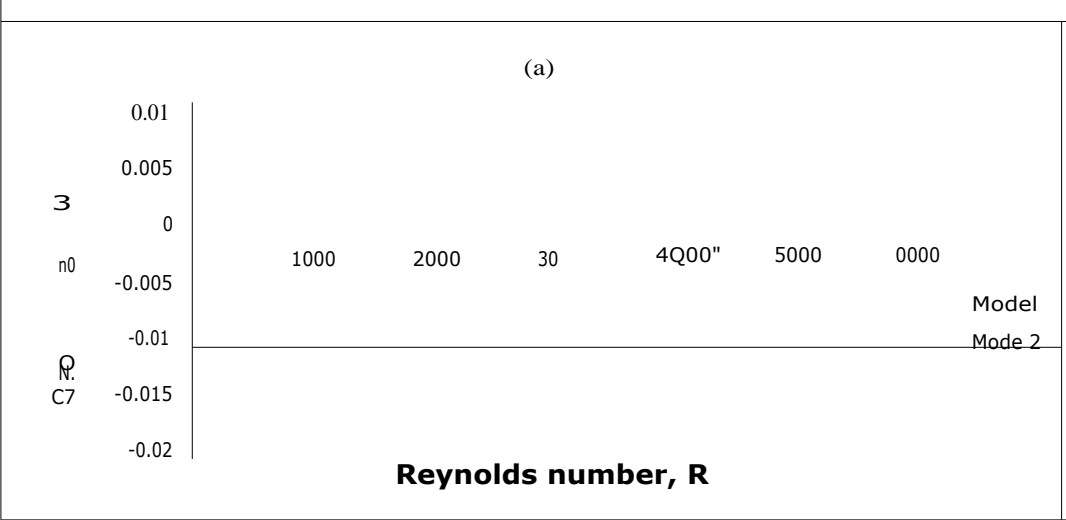

II (f. 5. Varialinn of the (a) growth rate, (ut,,) and (b) circular frequency ( a ) with $\mathrm{R}$ for $\mathrm{r}:,, 0.1, \mathrm{X}_{1}=0.2$,

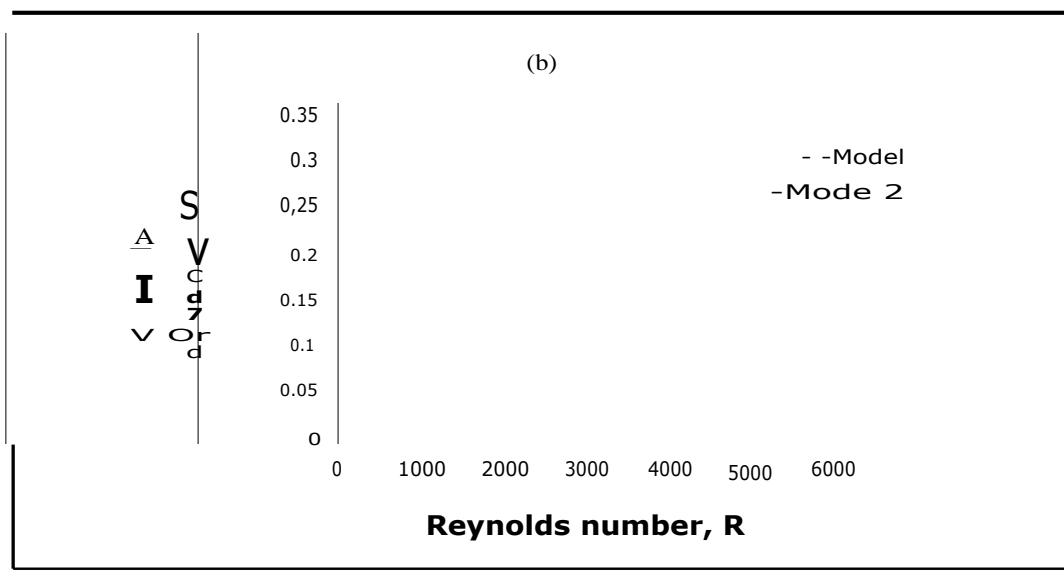
and $n^{\prime} \quad \mid$ (12. 150 .

$$
\begin{aligned}
& \left.\left.\left.\left.+12 C A_{4}\right) \quad+12 \quad t\right)(\mathrm{I}-\mathrm{x} 2)\right\} \mathrm{S} 2 \text {, (rr }\right)
\end{aligned}
$$

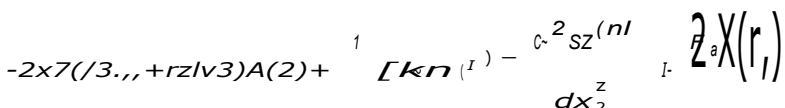$$
=0,
$$

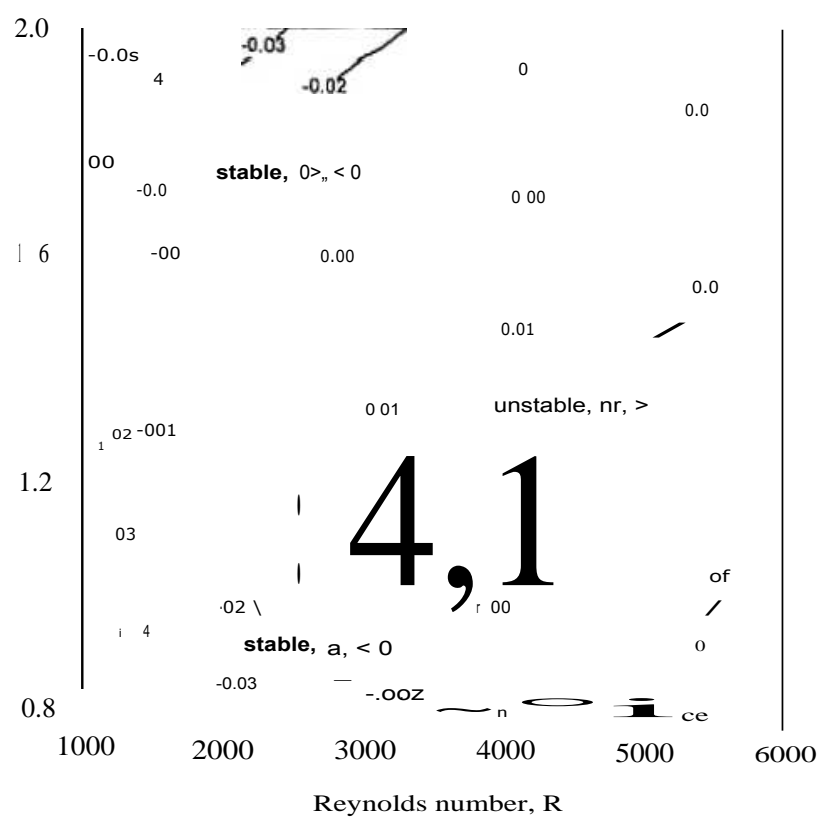

FIG. 6. Neutral stability characteristics of the $2 \mathrm{D}$ wavy channel flow in the wavenumber-Reynolds number $(\mathrm{a},-\mathrm{R})$ plane-contours of the constant growth rate/decay rate, $(\mathrm{w}, . ;)$ for the basic flow parameters, $\mathrm{X}_{\mathrm{I}}=0.2, \mathrm{co}_{\mathrm{w}}$ $=0,0$ where $11 "$ ", Stands For

$\mathrm{U} 101=(\sim 3 \ldots \mathrm{I}-)) \sim, 4) \sim \mathrm{s} ! \mathrm{it} \quad(\mathrm{rl},, \mathrm{f} . \gg \mathrm{AI}) \sim,$. iil an(1 the gt1Ullity $X^{1 '}$ ) in $\mid a l .(17)$ is a sum ol'twelve terms, i.c.,

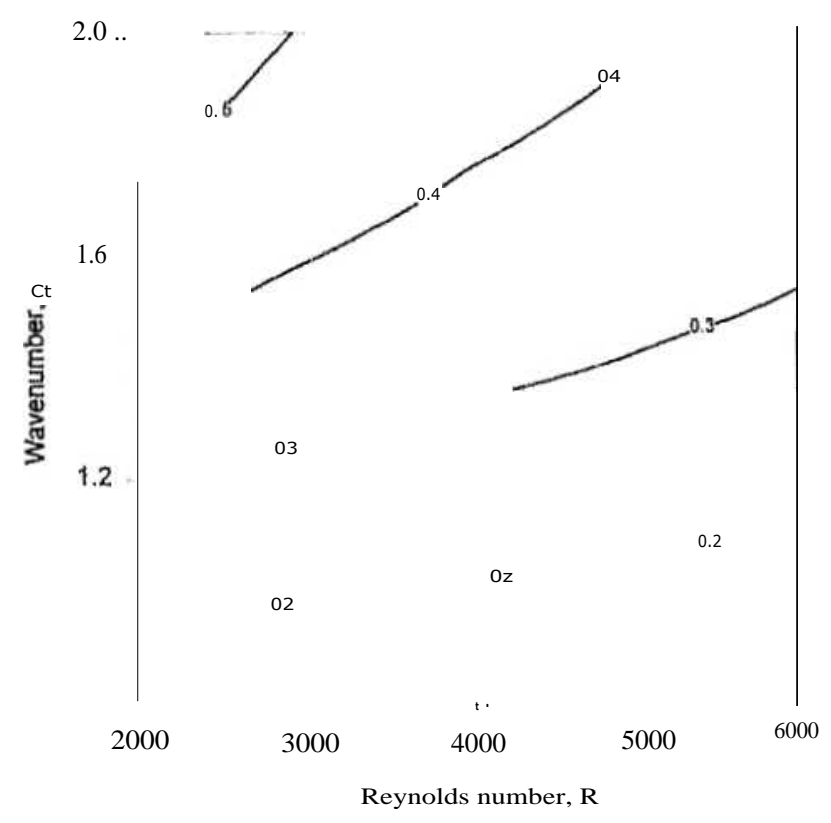

fo(i, 7. Neutral stability chtn'lucteristics ul' the 21) wavy channel flow in the wavenunther--Reynolds no ither ( $r r$, . R) plane--cunfours of const; uttcircu $I_{\mathrm{v}}$ frequency $(\mathrm{tu}, .$.$) for the basic flow paranutet:e,$ $=0.1$. 


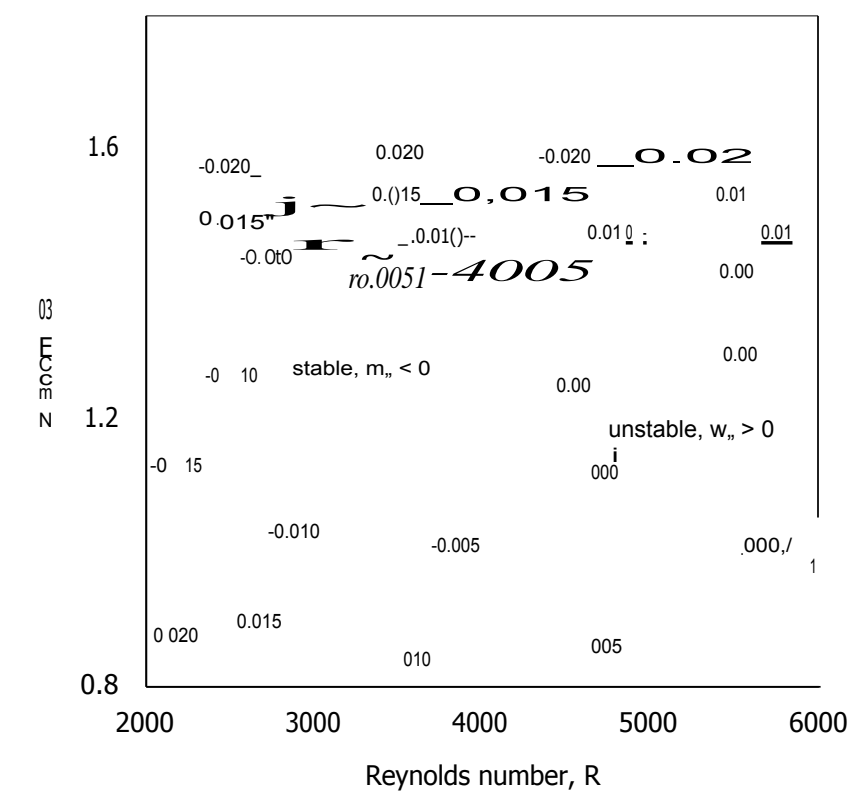

FIG. 8. Neutral stability characteristics of the $2 \mathrm{D}$ wavy channel flow in the wavenumber-Reynolds number $(\mathrm{a},-$ - $\mathrm{R})$ plane-contours of the constant growth rate/decay rate, $\left(\mathrm{ro}_{t 11}\right)$ for the basic flow parameters, $\mathrm{X} 1=0.2, \mathrm{w}_{\mathrm{h}}$ $=0.0, e_{,},=0.05$.

$$
\boldsymbol{X}(n) \underbrace{12}_{\mathbf{J}=\mathbf{1}} X(n)
$$

The $\mathrm{X}($ ") are listed in Appendix B.

Equations (14) and (17) together with the continuity, Eq. (I 2a), are the set of equations for the complex amplitude functions of the velocity Asj), A(2), and As"). The bound ary conditions are

$$
\text { A } \left.\mathrm{J}^{\prime}\right) 152-\quad 0, \quad \mathrm{j}=1,2,3 \text {. }
$$

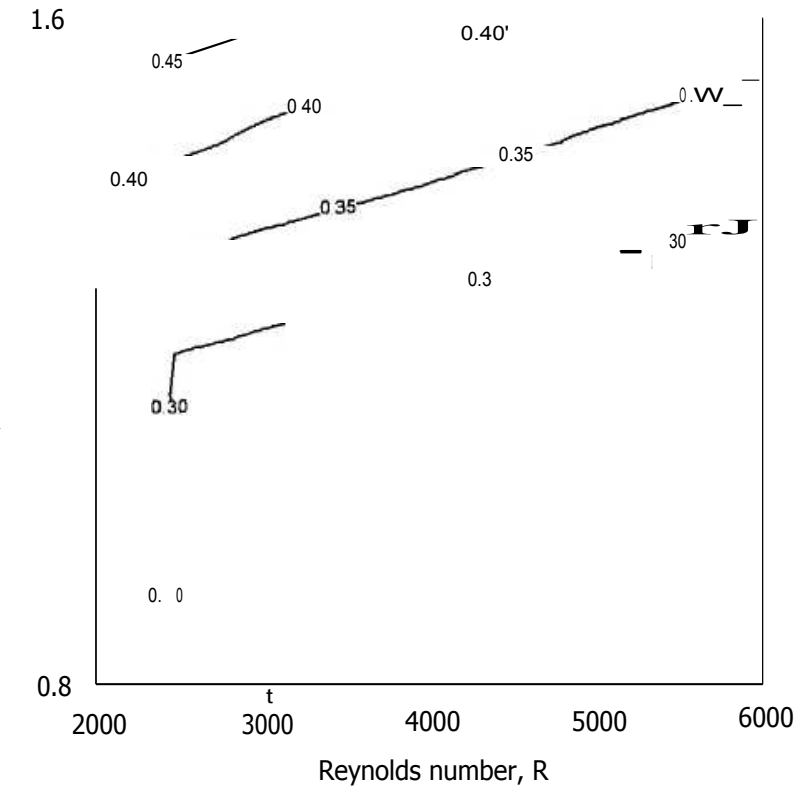

FIG. 9. Neutral stability characteristics of the $2 \mathrm{D}$ wavy channel flow in the wavenumber-Reynolds number $(\mathrm{a},-\mathrm{R})$ plane-contours of constant circular frequency, $(\mathrm{U}), . .$.$) for the basic flow parameters, \mathrm{X} 1=0.2$, $=0.05$

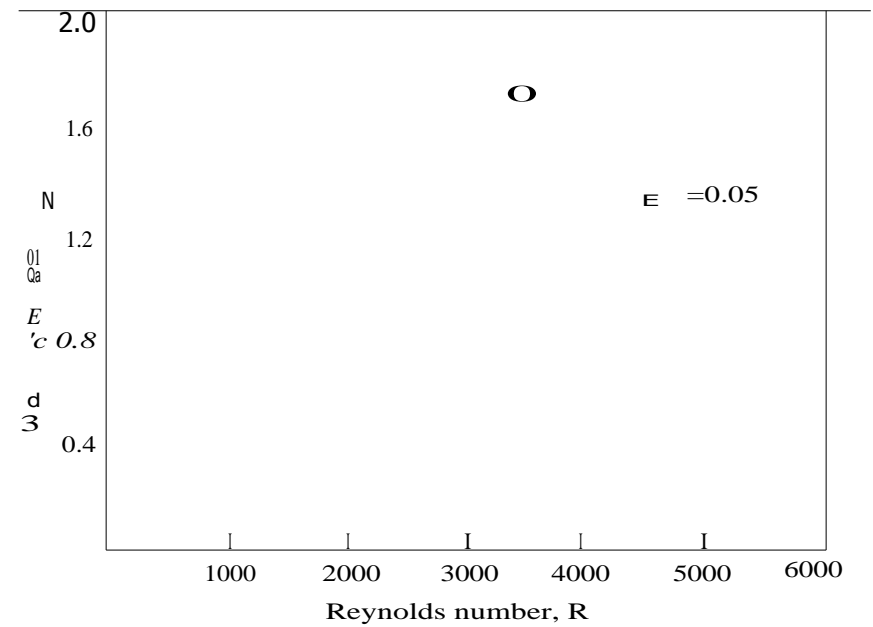

FIG. 10. Variation of the neutral stability characteristics for the $2 \mathrm{D}$ wavy channel flow in the $(\mathrm{a},-R)$ plane, $\mathrm{X} \quad 0.2, \mathrm{c}_{\mathrm{s}}=0.0$ for $\mathrm{s}, .,=0.0,0.05$, and 0.1

This reduces to an eigenvalue problem requiring a solution of the dispersion relation [i.e., Eq. (11)] for the complex frequency, to,.

A cursory inspection of the governing equations (14) and (17), shows that for the case of an unexcited wall ( $\mathrm{s}, . .=0)$, they reduce to the Orr-Sommerfeld equation for As' $t$ and the Squire equation for S2 ${ }^{(")}$. For s,..00, Eqs. (12a), (14), and (17) form an infinite set of coupled equations. Following the usual methodology,"' 9 we truncate them at $\mathrm{rt}=+1$ and $\mathrm{n}$ -1 , setting $\mathrm{A}^{1} !^{3}=0$ for all $n>1$ and $n<-1$. We then have nine unknowns, viz.,

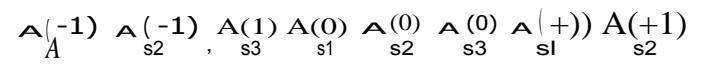

and

$$
\text { A53 }{ }^{(+1)}
$$

The nine equations for these are obtainable by writing Eqs. (12a), (14), and (17) for $\mathrm{n}=-1,0$, and +1 . The differ-

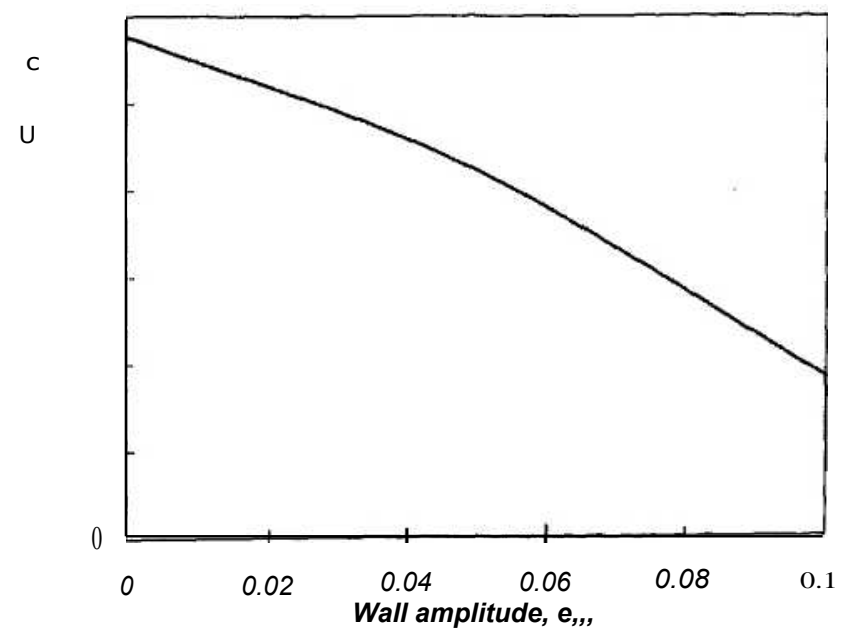

FIG. I I. Variation of critical Reynolds number for transition, $R c_{i} \mid r$,.) with amplitude of the converging-diverging symmetric wavy walled channel flow for $\mathrm{X}_{1}=0.2, \mathrm{X}_{3}=0.0$, and $\mathrm{w},=0.0$. 


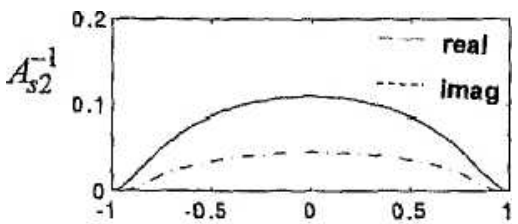

"Is|
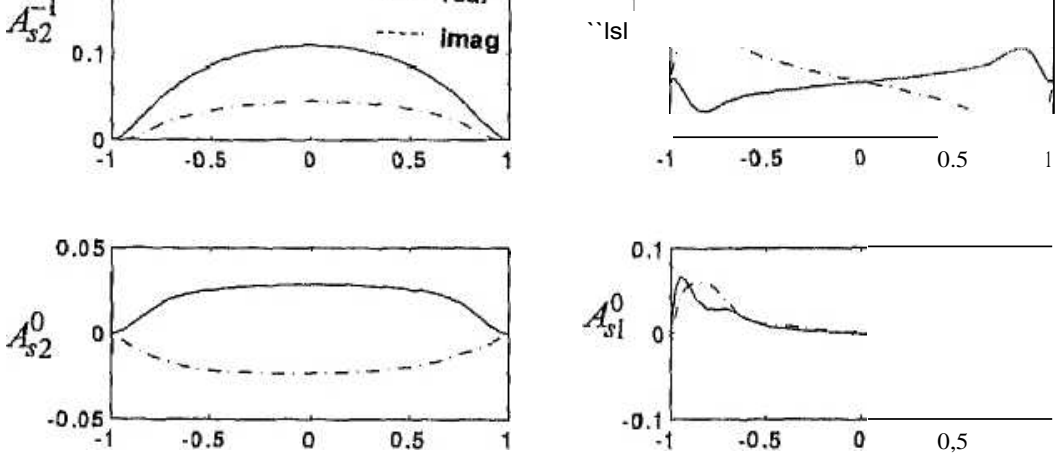

FIG. 12. Variation of the real and imaginary parts of amplitude functions u1' the disturbance across the channel Cor $\mathrm{R} \quad$ 1838, $\mathrm{A}_{\mathrm{i}}=-\left(1.2\right.$, ce, $\quad$ |A. ${ }^{\mathrm{r},,}=0,1$, and anel Cor R
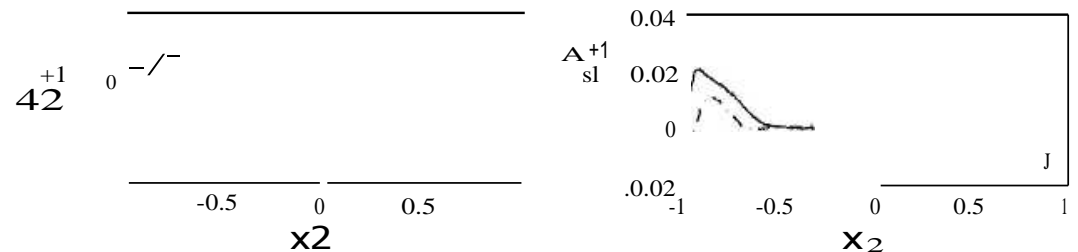

ential eigenvalue problem is solved after setting up the algebraic matrix equations. Following Selvarajan el al.17 an Floryan, "' using 41 collocation points, which are sufficient for obtaining accurate solutions, the size of the matrix to he solved for the eigenvalue problem is [369X369]. The generalized eigenvalue problem is solved using the MATLAI3 routines.

\section{RESULTS AND DISCUSSION}

\section{A. Validation}

The limiting case for the flow through the wavy walled channel is the calculation of the stability of plane Poiscuille flow as the amplitude of the wall and the wavenumber are se
C(1111,11 to zero. The results $01^{\prime} 111 C$ present stability calculations give the critical Reynolds nun)her of 5772.22 which is in good agreement with C)rszag. ${ }^{\text {jl) }}$

\section{B. Stability of flow through wavy walled channels}

The etl'ect of the wall amplitude parameter $\mathrm{a},$, , on the stability characteristics is examined for the basic flow of the wavy channel discussed in Sec. $11 \mathrm{~A}$ and also shown in Figs. 2 and 3(a)-3(h). The computations are carried out at $\mathrm{R}$ $=5772$ and the disturbance wavenuniber, $c, Y_{, .,}=1.02056$, as these values represent the critical parameters for the plane channel flows, It may be noted that the wavenunlber of the wall $\mathrm{X}_{1}=(1.2$ is widely separated from the shorter wavelength Or,) of the disturbance. The results or the stability
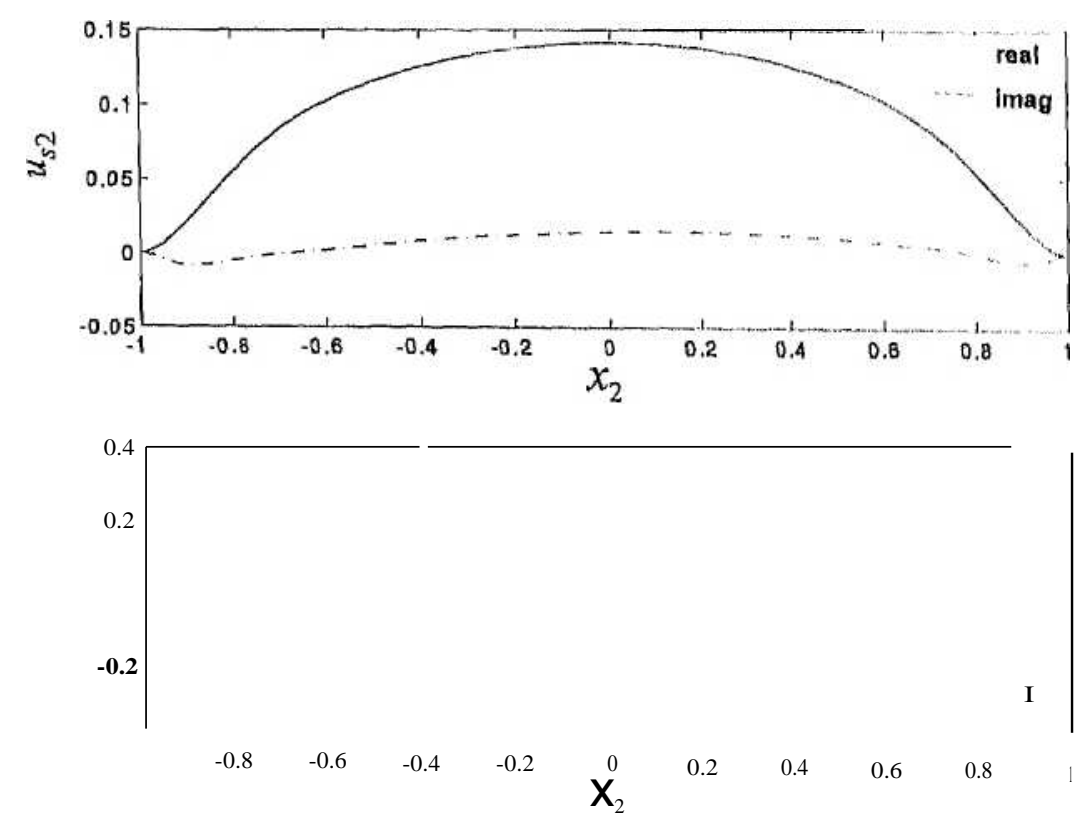

$\mathrm{V} 1(1,13$. The vuriatiun $\mathrm{nl}$ ' cli.wtin'ballee velocities across I ho channel for (lie pur+uncuers $R \quad$ i 838, $A_{i}=0,2,0$ IA, $r,,, \quad(1.1 \text {, and } u)_{4} \quad(1.1)$ 


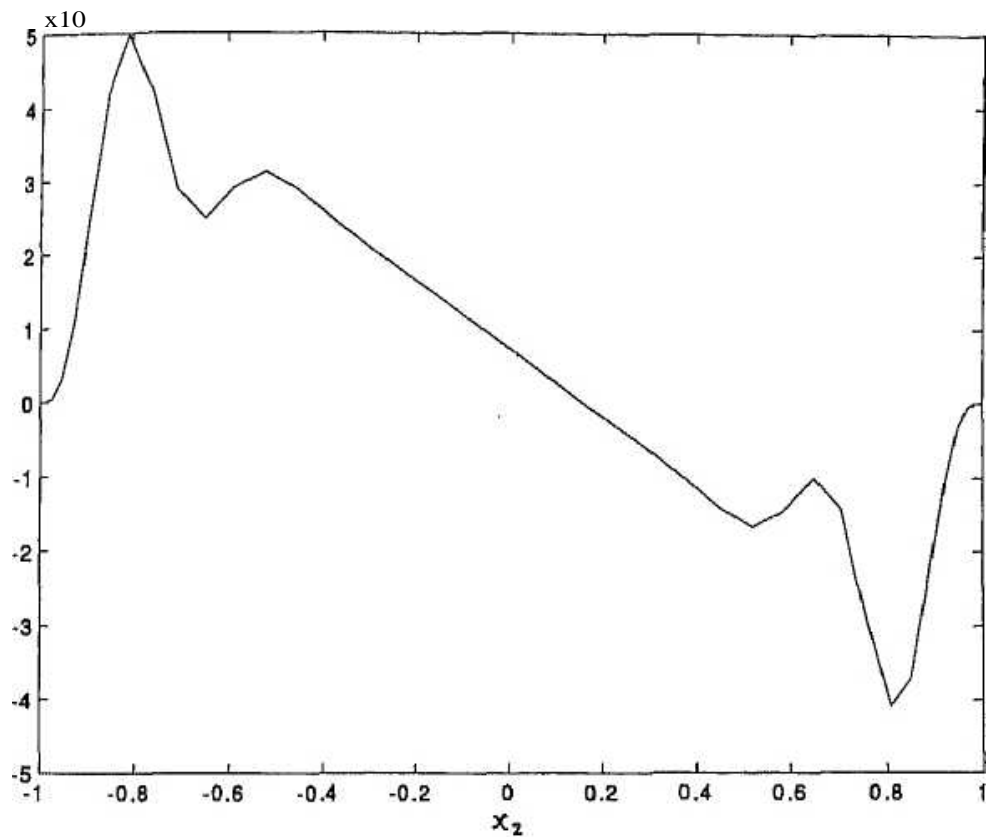

FIG. 14. Variation of the Reynolds stress distribution $\mathrm{S}(\mathrm{x}$,$) of the disturbances in the wavy channel flow for$ $\mathrm{R}=1838,1 ._{\mathrm{i}}=0.2, \mathrm{a}_{-},=1.4, \mathrm{e}, . .=0.1$, and $\mathrm{w}_{\mathrm{s}}=0.0$

calculations are given in Table I. The first mode indicates a slow growth of a mode resembling a Tollmien-Schlichting wave with a slightly decreasing circular frequency, $W_{s r}$. The second and higher modes are damped for $\mathrm{s}, . .<0.07$, as indicated by negative values of respective oh,. The appearance of a fast growing second mode, when $\mathrm{s},,,=0.07$ is indicative of the coupling between the wall wavenumber and the disturbance wavenumber while the circular frequency of the second mode co,.. is seen to decrease with $\mathrm{E},,$. . Calculations show that the circular frequency of the second mode approximately corresponds to the circular frequency of the of the plane channel flow with the disturbance wavenumber equal to $\left(a_{s}+x_{t}\right)$. Lessen and Gangwani ${ }^{20}$ also reported the ap- pearance of a fast growing mode for boundary layer flows. As $s$, is increased, some more unstable modes appear (see Table I). It may be mentioned that Guzman and Amon," in a direct numerical simulation of flow in a wavy channel, observe the occurrence of multiple unstable modes which correspond to self-sustained oscillatory flows. However, the circular frequencies of fast growing modes are lower than the frequency of the T-S wave. The relative growth of the unstable modes for $\mathrm{a}_{,}=0.95$ and $\mathrm{a}_{\mathrm{s}}=1.1$ are shown in Fig. 4 . The growth of the most unstable disturbances as the Reynolds number is varied is shown in Fig. 5.

In order to obtain the neutral stability characteristics of the chosen basic flow, a number of computations are carried

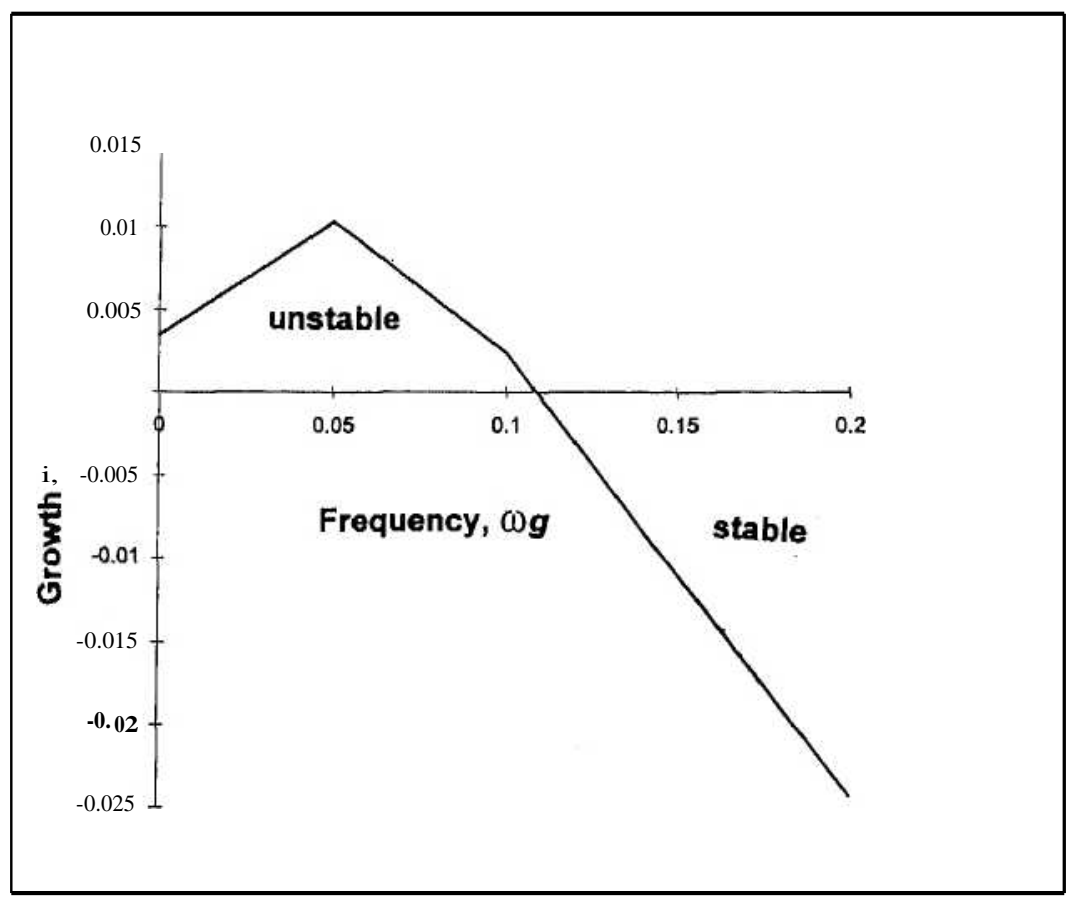

FIG. 15. Variation of the growth rate, $\left(\mathrm{ca}_{-},\right)_{\text {) with a fre- }}$ quency of excitation $\left(\mathrm{m}_{\mathrm{s}}\right)$ for $\mathrm{R}=2000, \mathrm{X},=0.2, \mathrm{~s}$,", $=0.1$, and $\mathrm{a}_{-},=1.4$. 


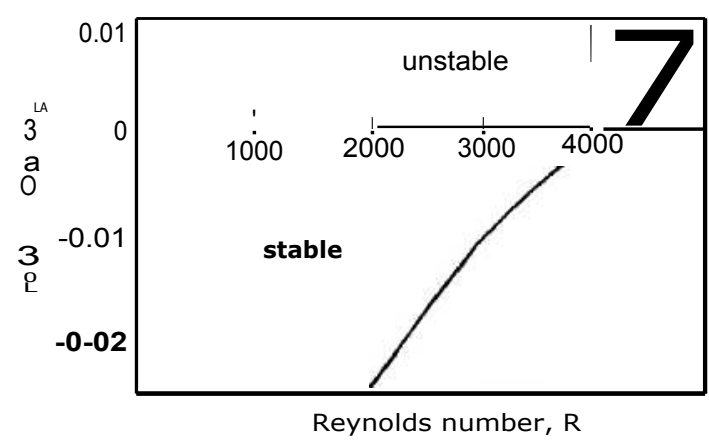

FIG. 16. Variation of the growth rate, (w,;) with Reynolds number $\mathrm{R}$ for the $2 \mathrm{D}$ wavy channel, $\mathrm{X},=0.2, \mathrm{e}, .=0.1, \mathrm{a}, .=1.4$ and subjected to frequency of excitation, $\mathrm{w}_{\mathrm{x}}=0,2$

out in the $\left(\mathrm{x},-\mathrm{R}\right.$ domain with $\mathrm{X}_{\mathrm{I}}=0.2, \mathrm{e},,,=0.1$, and $\mathrm{w}$, $=0.0$. Figures 6 and 7 show the contours of constant $w$,; and constant co, $r$. The transition critical Reynolds number, Rcr(Lran) below which all the disturbances are damped, is 1838 for $\mathrm{E},,=0.1$. When calculations are repeated for $\mathrm{e}$, $=0.05$, the critical Reynolds number, $\operatorname{Rcr}\left(\operatorname{tr}_{,}, n_{\text {, }}\right)$ is 4207 , whose results are presented in Figs. 8 and 9. As a summary of results, the neutral stability characteristics and the limit of stability, i.e., in the linear sense, the critical Reynolds number for transition $\left.\mathrm{R}_{\mathrm{Cr}(\text { Iran }}\right)$ for the wavy channel flow with the variation of the wall amplitude parameter E,,, are shown in Figs. 10-11, respectively. Typical variations of the amplitude functions and the disturbance velocities for the critical parameters of the wavy channel are also shown in Figs. 1213, respectively. Following Drazin and Reid, ${ }^{21}$ the variation of the Reynolds stress distribution ${ }^{21}$ is plotted in Fig. 14. It is indicative of the transfer of energy from the mean flow to the disturbance and the kinks indicate the existence of more than one critical layer.

\section{Effect of frequency of excitation}

It is of interest to study the effect of imposed circular frequency $w_{t}$ on the stability characteristics of the converging-diverging wavy channel flow, For I R $=2000, X_{1}=0.2$, and $c r,=1.4$, the decay/growth rate of the disturbance was computed by varying the excitation frequency, $w_{t}$. The results are shown in Fig. 15. It is interesting to note that for this $E,,=0.1$, for which the unexcited (rigid) wavy channel now is unstable (for $R>1837$ ), the flow now becomes stable for $c o,=0.11$. With $(\mathrm{on}=0.2$ and a further variation of the Reynolds number, the disturbance becomes neutrally stable only at about $R=4200$, as shown in Fig. 16 . This demonstrates that the transition to turbulent process may be delayed by a suitable excitation of the wall. It may be added that Guzman and Amon ${ }^{22}$ and Anion et (11. have shown that even unstable but controlled oscillatory regimes with Lagrangian and Eulerian chaos improve fluid mixing and can lead to a lower pumping power. However, in the present case of forced excitation, the power required l'or wall motion needs to be taken into account. Further investigation may be needed to determine the effect of wall waviness on the nonlinear growth of disturbances.

\section{CONCLUDING REMARKS}

The temporal stability characteristics of a periodic basic flow due to a wavy channel have been studied using the Floquct theory. The transition critical Reynolds number for the rigid wavy walled channel flow is shown to decrease with an increase of $\mathrm{E}$, , . It is also shown that the channel flow can be modulated by a suitable excitation of the wavy walls,

\section{ACKNOWLEDGMENTS}

A part of this work was done when the authors (S,S. and E.G.T.) visited the RuhrUniversitat liochum, Germany under a DAAD Fellowship scheme. The authors are grateful to professor K. Gersten, 1)r. W. Koch, and Dr. T. K. Sengupta for helpful discussions. 'i'he authors acknowledge useful sug. gest.ions given by the referees.

\section{APPENDIX A' PARASITIC COEFFICIENTS Air}

The du anlities 'It' ${ }^{i I}$ arc listed as given below: Air 1..) a. I)) $\left.\backslash_{1}\right] l i_{3}+\frac{d}{d x 2}$

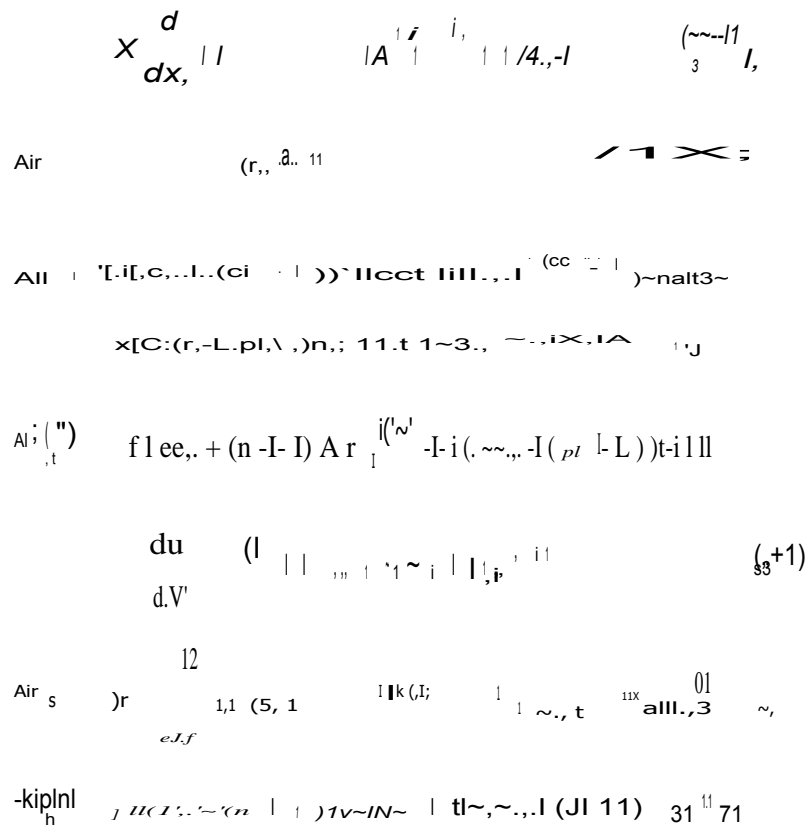

XI Icr, t it $X$ ]n;; "' 1 L/3, -t it X3IIIY"' I)|

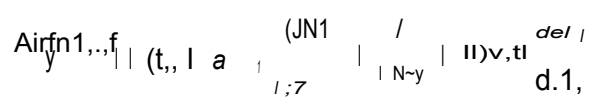
il.

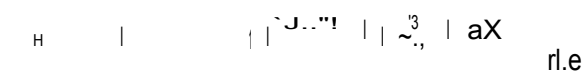

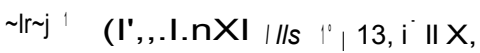

(I/f I" 


$$
\begin{aligned}
& { }_{41}{ }_{10}^{d u n^{\prime}}-\left[a_{s}+n X 1\right] 1 \sim_{2}^{-}[[c C 3, .+n X 3] d \% z 3 \\
& \left.X-Z A I A s j+l)-i A 3 A s 3+1)+\cdot d A_{2(1+1)} d x_{2}\right),
\end{aligned}
$$

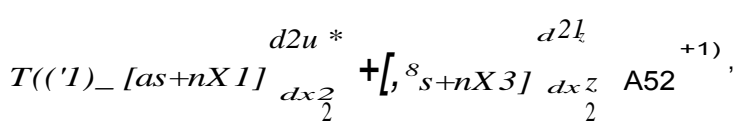

$$
\begin{aligned}
& n \sim 12)-\left[[a,+n \sim l] t t l+\left[R s^{\prime}+{ }^{11} X 3\right] u 3 J\right. \\
& X-l \text { 八 } \frac{d A s l}{\underline{+11)}}-{ }_{t} \sim \frac{d A s 3}{d x 2} \frac{+12}{!}, \\
& \left.\mathrm{r}^{\prime}\right)^{\prime}=1 c^{2} E\left[\left[a^{\prime}+(n-1) X 1\right] t c\left[+\left[/ 3 s+\left(n^{-1}\right) X 3\right] t t 3\right] A s 2^{-' 1}\right. \\
& \left.+\left[[a, .+(n .+1) \sim 1] u i+{ }_{1 J^{\sigma}},+\left({ }^{11+}{ }^{1}\right) \sim 3\right] u\right] A s 2^{+1)}
\end{aligned}
$$

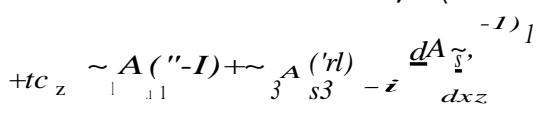

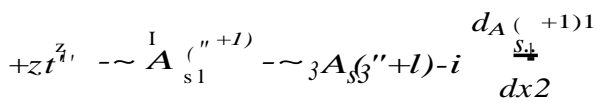

$$
\begin{aligned}
& -i_{\mathrm{d}} \times 2 \mathrm{A52-1)- \textrm {i }} d \times 2 \text { A } s^{\prime} 2
\end{aligned}
$$

\section{APPENDIX B: THE PARASITIC COEFFICIENTS X}

The quantities $X \sim$ ") are listed as given below:

$\left.X s^{\prime \prime}\right)=i u l[a s+(n-1) X I][[P s+n) 53] A ;(i-1)$

$-[c r s+n X 1] A s 3-1)]$,

$$
X_{2^{\prime \prime}}{ }^{\prime}={ }_{U 2} \chi_{2}\left[\left[, 8_{\mathrm{s}}+n A_{3}\right] A s^{-1)}-\left[a_{\mathrm{s}}+n X_{1}\right] \mathrm{As} \sim^{-1)}\right],
$$

$X \sim ")=\operatorname{in} 3[, 3, .+(n-1) \times 3]\left[[p s .+n \times 3] A S^{\prime} 1-l\right)$

$$
-[a, .+n A l] A\left(A n_{-}{ }^{1)}\right.
$$

$\left.X_{4}^{(\prime \prime)}=i l l_{1}^{\prime \prime} a_{\mathrm{s}}+(n+1) X 1\right][[(3, .+11 X 3] A(j+1)$

$$
\left.\left.\left.X S^{\prime \prime \prime}=u z^{\prime} d x_{2}+n .\right), l\right] A ;^{\prime} \sim+{ }^{\prime \prime}\right],
$$$$
\left.X l f i ")=i C t 3 * E \$ .+(n .+1) 1 v 3] \quad+17 X_{3}\right] A^{\prime} S^{+1)}
$$

$$
\left.-\left[a_{s:}+n X_{1}\right] A^{(i, l)}\right] \text {, }
$$$$
\left.X Y^{\prime \prime} \quad+I I \quad{ }_{3}\right] u_{l}-\left[a_{3} .+n A_{l}\right] u_{3} Y X A
$$

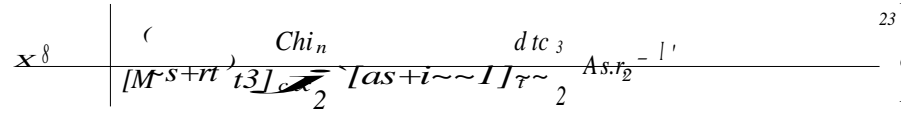

'T. Herbert, "Secondary instability of boundary layers, " Anna, Rev. Fluid Mech. 20, 487 (1988).

${ }^{2}$ M. V. Morkovin, "Many faces of transition," in Viscous Drag Reduction, edited by C. S. Wells (Plenum, New York, 1969).

${ }^{3}$ H. L. Reed and W. S. Saric, "Linear stability theory applied to boundary layers, " A nnu. Rev. Fluid Mech. 28, 389 (1996).

${ }^{4}$ T. B. Benjamin, "Shearing flow over a wavy boundary," L Fluid Mech. 6 161 (1959).

${ }^{5}$ T. B. Benjamin, "Effects of a flexible boundary on hydrodynamic stability," J. Fluid Mech. 9, 513 (1960).

${ }^{6} M . T$. Landahl, "On the stability of laminar incompressible flow over a flexible surface," J. Fluid Mech. 13, 609 (1961),

F. D. Hains and J. F. Price, "Effect of a flexible wall on the stability of plane Poiseuille flow," Phys. Fluids 5, 365 (1962).

${ }^{5}$ C. E. Grosch and H. Salwen, "The stability of steady and time-dependent plane Poiscuille flow," J. Fluid Mech. 34, 177 (1968).

${ }^{9}$ C. H. von Kerezek, "The instability of oscillatory plane Poiseuille flow," J. Fluid Mech. 116, 91 (1982).

$1^{\circ}$ B. A. Singer, J. H. Ferziger, and H. L. Reed, "Numerical simulations of transition in oscillatory plane channel flow, "J. Fluid Mech. 208, 45 (1987)

"A. M. Guzman and C. H. Amon, "Transition to chaos in convergingdiverging channel flows: Ruelle-Takens-Newhouse scenario," Phys. Flu${ }_{12}$ ids 6, 1994 (1994).

J. M. Floryan, "Stability of wall bounded shear layers in the presence of ${ }_{13}$ simulated distributed surface roughness," J. Fluid Mech. 335, 29 (1997). ${ }^{13}$ S. Selvarajan and V. Vasanta Ram, "Dynamical characteristics of waveexcited channel flow," Sadhana 19, 349 (1994).

'"M. Van Dyke, Perturbation Methods in Fluid Mechanics (Parabolic Stan${ }_{L}$ ford, CA, 1975).

M. R. Scott and H. A. Watts, "Computational solution of linear two-point boundary value problems via orthonormalization," SIA M (Soc. Ind. Appl. Math.) J. Math. Anal. 14, 40 (1977).

${ }^{16}$ C. Canuto, M. Y. Hussaini, A. Quarteroni, and T. A. Zang, Spectral Methods in Fluid Dynamics (Springer-Verlag, Heidelberg, 1988).

${ }^{17}$ S. Selvarajan, E. G. Tulapurkara, and V. Vasanta Ram, "A numerical simulation of flow through wavy walled channels, "Int. J. Opt. Comput. 26. 519 (1998)

${ }^{8}$ S. A. Codington and N. Levinson, Theory of Ordinary Differential Equations (McGraw-Hill, New York, 1965).

'5. A. Orszag, "Accurate solution of the Orr-Sommerfeld stability equation," J. Fluid Mech. 50, 689 (1971).

${ }^{2} O M$. Lessen and S. T. Gangwani, "Effect of small amplitude wall waviness upon die stability of the laminar boundary layer," Phys. Fluids 19, 510 ${ }_{21}(1976)$.

P. G. Drazin and W. H. Reid, Hydrodynamic Stability (Cambridge University Press, Cambridge, 1981).

${ }^{22}$ A. M. Guzman and C. H. Amon, "Dynamical flow characterization of transitional and chaotic regimes in converging diverging channels, "J. Fluid Mech. 321, 25 (1996).

${ }^{23}$ C. H. Amon, A. M. Guzman, and B. Morel, "Lagrangian chaos, Eulerian chaos, and mixing enhancement in converging-diverging channel flows," Phys. Fluids 8, 1192 (1996). 